DOI: 10.29303/jrpb.v8i1.151

ISSN 2301-8119, e-ISSN 2443-1354

Tersedia online di http://jrpb.unram.ac.id/

\title{
APLIKASI PENGOLAHAN CITRA UNTUK PROSES SORTASI BUAH MANGGA BERDASARKAN DIMENSI DAN BOBOT
}

\author{
Image Processing Application for Mangoes Sortation Based on Dimension and Weight \\ Setya Permana Sutisna*), Roy Waluyo, Fahmi Aldiansyah, Mamat Rahmat \\ Program Studi Teknik Mesin, Universitas Ibn Khaldun Bogor \\ J1. Sholeh Iskandar Km.2, Kedung Badak, Bogor 16162, Indonesia \\ Email*): setya.permana@uika-bogor.ac.id \\ Diterima: September 2019 \\ Disetujui: Februari 2020
}

\begin{abstract}
Mangoes have different sizes and weights. Sometimes farmers still use manual methods to distinguish the quality of mangoes. The manual method is often inaccurate and inconsistent because every human being has their perception. Based on these problems a mango sorter machine was been designed using image processing techniques. This study starts with collecting information on the quality parameters of mangoes and studying the concept of image processing in the process of determining the quality and sorting of fruit. This study only focused on the parameters of dimensions and weights. The grouping of mangoes using weights based on statistical samples. Mangoes were divided into three groups, $A, B$, and C. Group A, B, and $C$ have weight of greater than $350 \mathrm{~g}$, between $200 \mathrm{~g}-350 \mathrm{~g}$, and less than $200 \mathrm{~g}$, respectively. The image capture room is designed to be closed and equipped with an image acquisition system using a webcam with 3 Megapixel resolutions producing $352 \times 288$ pixels. The image was mapped into two-dimensional coordinates; each point consists of one pixel using the frame grabber component. Calibration used $100 \mathrm{~kg}$ random mango sample. Results showed correlation between the number of pixels and the surface area of mangoes. The image processing algorithm able to estimate the surface area of mangoes with $R^{2}$ was 0.99 and $R S M E$ value was $0.19 \mathrm{~cm}^{2}$. The dimensions and mango weight correlation test showed proportional values. Even so, with this method was an unfavorable with the coefficient determination $R^{2}$ results 0.76 and $R S M E$ values $26.53 \mathrm{~g}$.
\end{abstract}

Keywords: weight estimation, area estimation, image processing, mangoes sorting

\begin{abstract}
ABSTRAK
Mangga memiliki ukuran dan bobot yang berbeda. Terkadang para petani masih menggunakan cara manual dalam membedakan mutu mangga. Cara manual sering kali tidak akurat dan konsisten dikarenakan setiap manusia memiliki persepsi masing-masing. Berdasarkan masalah tersebut telah dirancang sebuah mesin sortasi mangga menggunakan teknik pengolahan citra. Penelitian ini dimulai dari pengumpulan informasi parameter mutu buah mangga serta mempelajari konsep pengolahan citra dalam proses penentuan mutu dan sortasi buah. Penelitian ini hanya difokuskan pada parameter dimensi dan bobot. Pengelompokan buah
\end{abstract}


mangga menggunakan bobot dilakukan berdasarkan statistik sampel buah mangga yang digunakan. Mangga dibagi ke dalam tiga kelompok yaitu A, B, dan C. Kelompok A dengan bobot mangga lebih besar dari $350 \mathrm{~g}$, B dengan bobot mangga antara $200 \mathrm{~g}-350 \mathrm{~g}$, dan $\mathrm{C}$ dengan bobot kurang dari $200 \mathrm{~g}$. Ruang pengambilan citra didesain tertutup dan dilengkapi sistem akuisisi citra menggunakan webcam dengan resolusi 3 Megapixel sehingga mampu menghasilkan citra sebesar 352 x 288 pixel. Citra dipetakan ke dalam koordinat dua dimensi yang setiap titiknya terdiri dari satu pixel menggunakan komponen frame grabber. Pengujian menggunakan sampel mangga sejumlah $100 \mathrm{~kg}$ secara acak. Berdasarkan hasil pengujian hubungan jumlah pixel terhadap luas permukaan buah mangga diperoleh bahwa algoritma pengolahan citra yang dibuat telah mampu menduga luas permukaan mangga dengan $\mathrm{R}^{2}$ sebesar 0,99 dan nilai RSME sebesar $0,19 \mathrm{~cm}^{2}$. Hasil pengujian korelasi dimensi dan bobot mangga menunjukkan terdapat hubungan yang berbanding lurus. Meskipun demikian, pendugaan bobot dengan metode ini dapat dikatakan memiliki hasil $\mathrm{R}^{2}$ hanya sebesar 0,76 dan nilai RSME sebesar 26,53 g.

Kata kunci: pendugaan bobot, pendugaan dimensi, pengolahan citra, sortasi mangga

\section{PENDAHULUAN}

\section{Latar Belakang}

Mangga (Mangifera indica L.) merupakan buah musiman yang banyak tumbuh di Indonesia dengan nilai komersial yang tinggi. Buah ini memiliki pasar yang luas baik di dalam negeri maupun ekspor karena memiliki cita rasa yang khas dan lezat. Hal ini menunjukkan mangga layak untuk diprioritaskan karena memiliki nilai keekonomian yang tinggi dan memiliki daya saing yang baik. Berdasarkan sistem informasi Badan Pusat Statistik (BPS) produksi mangga di Indonesia mencapai 2,2 juta ton dengan nilai ekspor sebesar 944 ribu US Dolar dalam bentuk segar maupun kering.

Proses sortasi dan pemutuan merupakan kegiatan pengelompokan produk berdasarkan parameter-parameter mutu yang digunakan (Anugrahandy, dkk., 2012). Sebagai upaya untuk menghasilkan mangga berkualitas sesuai permintaan pasar, berdasarkan ketentuan SNI 3164:2009 mutu mangga ditentukan oleh beberapa parameter di antaranya adalah bentuk, tampilan, benda asing dan kotoran, kerusakan, hama dan penyakit, serta tingkat kematangan. Penyortiran buah di Indonesia secara umum masih menggunakan metode konvensional, yaitu dengan menggunakan tenaga manusia. Hal ini memiliki kelemahan, yaitu penilaian tidak objektif serta tidak konsisten karena keterbatasan visual, keterampilan, kejenuhan, dan kelelahan. Untuk mengatasi hal tersebut, diperlukan penerapan sistem cerdas yang dapat melakukan pemilahan secara otomatis (Pramanta, dkk., 2017).

Penggunaan pengolahan citra dalam proses sortasi buah merupakan upaya untuk menggantikan pengamatan visual oleh manusia pada proses sortasi secara konvensional. Teknologi pengolahan citra merupakan salah satu teknologi yang dikembangkan untuk mendapatkan informasi dari suatu citra dengan memodifikasi citra sehingga menghasilkan citra lain yang lebih informatif (Jain, dkk., 1995).

Beberapa penelitian pengembangan mesin sortasi dengan menggunakan pengolahan citra di antaranya adalah pengembangan mesin sortasi jeruk (Ahmad, dkk., 2008), sortasi buah manggis (Kastaman, dkk., 2008), sortasi buah tomat (Thiang, 2008), sortasi kopi beras (Soedibyo, dkk., 2010), dan sortasi buah pisang (Wiharja dan Harjoko, 2014).

\section{Tujuan}

Penelitian ini bertujuan untuk mengembangkan program aplikasi penentuan mutu buah berdasarkan bobot melalui pendugaan ukuran dan bobot buah mangga secara real time. 


\section{METODE PENELITIAN}

\section{Alat dan Bahan}

Peralatan yang digunakan dalam penelitian ini adalah komputer (PC) dilengkapi dengan software aplikasi Visual Basic 6.0, webcam resolusi maksimum 1280 x 720 pixels, kotak pengambilan gambar dengan ukuran $30 \mathrm{~cm} \times 40 \mathrm{~cm}$ x $40 \mathrm{~cm}$ dicat hitam dengan alas berwarna putih dan dilengkapi lampu LED strip $12 \mathrm{~W}$ sepanjang $1,5 \mathrm{~m}$. Bentuk kotak pengambilan citra dapat dilihat pada Gambar 1. Bahan yang digunakan dalam penelitian ini dan menjadi objek utama penelitian ini adalah mangga arumanis.

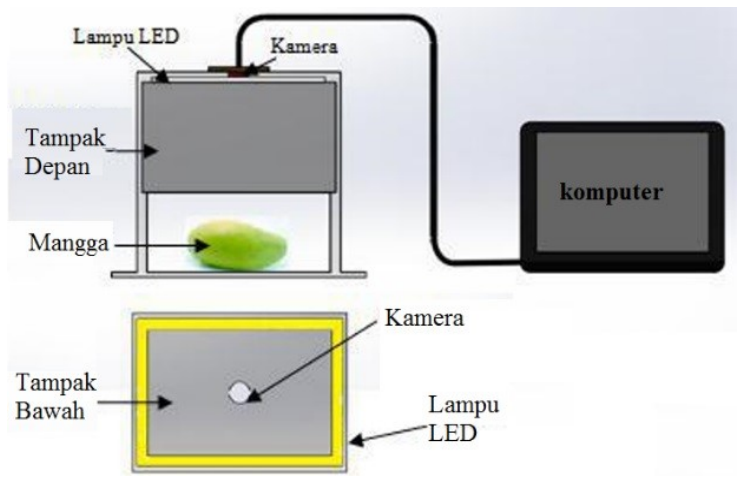

Gambar 1. Kotak pengambilan citra

\section{Metode}

Penelitian ini dimulai dari pengumpulan informasi parameter mutu buah mangga serta mempelajari konsep pengolahan citra dalam proses penentuan mutu dan sortasi buah. Terdapat beberapa parameter yang dapat digunakan dalam penentuan mutu buah menggunakan teknik pengolahan citra, namun dalam penelitian ini hanya difokuskan pada parameter dimensi dan bobot.

Bentuk ruang pengambilan citra dapat dilihat pada Gambar 1. Ruangan ini didesain tertutup agar mengurangi gangguan pencahayaan dari luar kotak yang dapat mempengaruhi warna tangkapan kamera. Kamera diletakkan pada bagian atas sehingga citra mangga yang tertangkap kamera hanya bagian mangga yang menghadap ke atas. Sekeliling kamera dilengkapi lampu LED sehingga mampu menghasilkan sistem pencahayaan yang memadai. Warna latar objek pengambilan gambar dibuat kontras terhadap warna buah untuk memudahkan proses pemisahan citra objek dan latar. Selain itu, terdapat dua celah pada sisi bawah kotak yang berfungsi sebagai tempat keluar masuk buah ketika kotak pengambilan gambar ini diintegrasikan pada konveyor.

Akuisisi citra menggunakan webcam yang disesuaikan sehingga menghasilkan gambar sebesar 352 × 288 pixel. Citra dipetakan ke dalam koordinat dua dimensi yang setiap titiknya terdiri dari satu pixel menggunakan komponen frame grabber. Proses digitasi dilakukan secara in situ dalam komponen kamera dan ditransfer melalui antar muka USB dengan perangkat lunak komputer secara realtime.

Kalibrasi citra dilakukan untuk mengetahui hubungan antara jumlah pixel objek citra terhadap dimensi mangga serta bobot mangga. Kegiatan kalibrasi diawali dengan mencari hubungan jumlah pixel terhadap luas benda dua dimensi berupa potongan kertas dengan ukuran luas yang telah diketahui. Hasil kalibrasi ini kemudian diujikan pada buah mangga secara acak sebanyak $100 \mathrm{~kg}$ sehingga diperoleh hubungan antara luas tersebut terhadap bobot mangga.

Aplikasi program komputer pengolahan citra dibangun menggunakan software Visual Basic 6.0. Program pengolahan citra dikembangkan agar dapat melakukan pengambilan citra, pengolahan citra, dan pengambilan keputusan secara realtime. Algoritma program dapat dilihat pada Gambar 2. Program dimulai dengan mengambil citra mangga. Selanjutnya, citra dilakukan proses thresholding untuk mendapatkan nilai derajat keabu-abuan. Kode program proses penentuan bobot dan dimensi dapat dilihat pada Gambar 3. Berdasarkan nilai keabu-abuan, citra dibinerisasi untuk memisahkan citra mangga dan latar. 


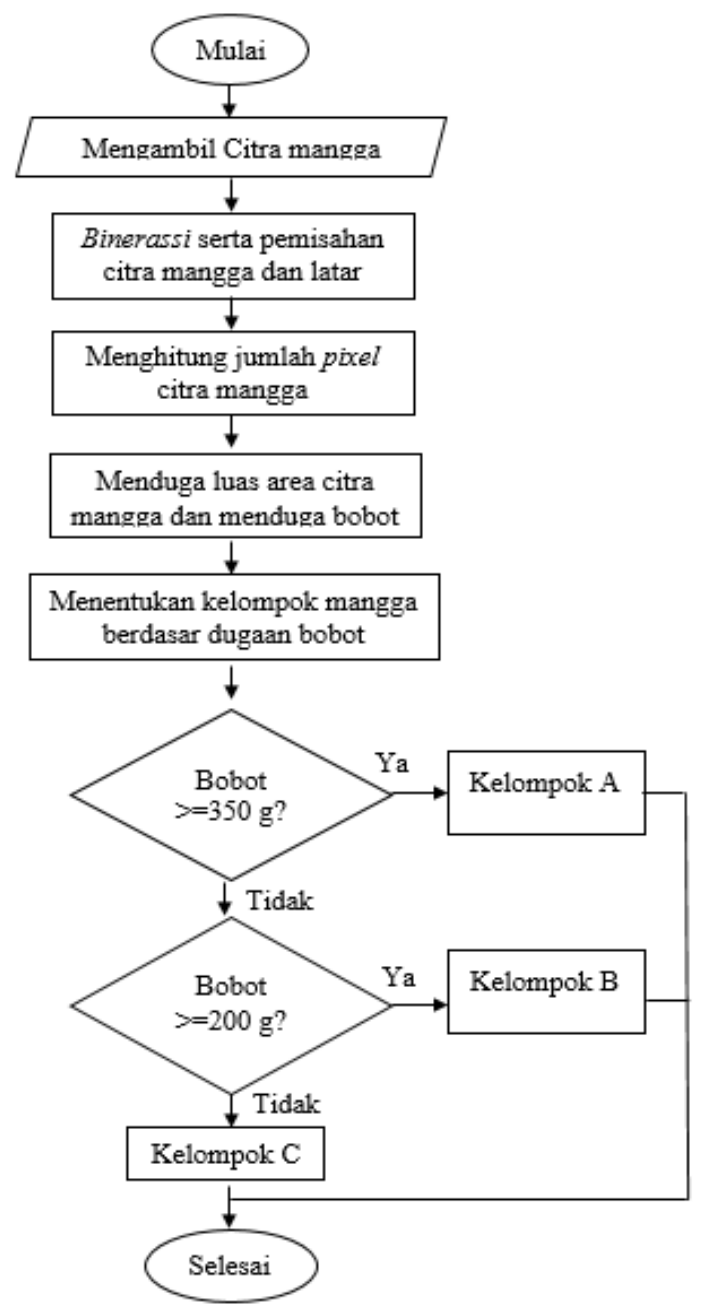

Gambar 2. Algoritma program pengelompokan mangga

Latar citra dipilih menggunakan warna yang kontras terhadap warna mangga. Pada penelitian ini, sebagai latar objek digunakan warna putih untuk memudahkan proses pemisahan objek dan latar objek. Setelah itu, program menghitung jumlah pixel objek gambar. Jumlah pixel objek gambar kemudian dikonversi ke nilai luas objek dan bobot mangga menggunakan persamaan kalibrasi. Berdasarkan nilai dugaan bobot program aplikasi, program kemudian memberi keputusan kelompok mangga yang telah diproses. Mangga dikelompokkan ke dalam tiga kelompok, yaitu kelompok A dengan ukuran besar (bobot lebih dari $350 \mathrm{~g}$ ), kelompok B berukuran sedang (bobot antara $200-350$ g), dan kelompok $\mathrm{C}$ adalah kelompok mangga berukuran kecil (bobot kurang dari
$200 \mathrm{~g}$ ). List kode program proses penentuan bobot dan dimensi dapat dilihat di bawah ini.

For $\mathrm{i}$ s To $\mathrm{x}$ Step 15

For $j=1$ To y Step 15

warna $=$ Picture2.Point $(i, j)$

$r=$ warna And $\operatorname{RGB}(223,0,0)$

$\mathrm{g}=\operatorname{Int}(($ warna And $\operatorname{RGB}(0,228,0)) / 228)$

b - Int(Int ((warna And $\operatorname{RGB}(\theta, 0,550))$ /

215) / 215)

If $(r>100$ And $g>100$ And $b>100)$ Then

Picture3.F5et (i, j), $\operatorname{RGB}(50,50,50)$

jum_pixel $=$ jum_pixel +1

End If

Next $J$

Next i

luas_cm $=(0.0081 *$ luas $)-0.0991$

bobot gram $=($ luas $\mathrm{cm} * 4.9452)-85.928$

If (bobot_gram $>=350$ ) Then

MSCoraml.Output = "a"

kelompok = "A"

Elself (bobot_gram $>=200$ ) Then

MSComml.Output = "b"

kelompolc = "B"

Elself (bobot_gram < 200) Then

MSComml. Output = "c"

kelompok = "C"

End If

\section{HASIL DAN PEMBAHASAN}

Tampilan program aplikasi pendugaan dimensi dan bobot mangga yang telah dibuat dapat dilihat pada Gambar 3. Untuk menjalankan program pertama kali dengan menekan tombol "Kamera ON" pada layar komputer. Tombol ini untuk mengaktifkan webcam yang terpasang pada komputer. Cuplikan gambar secara real time ditampilkan pada nomor 1 di Gambar 3. Ketika tombol "Ambil Gambar" ditekan pada layar komputer, cuplikan gambar saat itu akan terekam sebagai citra mangga yang akan diproses. Citra asli yang akan diproses dalam pengolahan citra ditampilkan pada nomor 2 di Gambar 3 dan selanjutnya hasil pemisahan mangga terhadap latar ditampilkan pada nomor 3 di Gambar 3. Nilai dugaan dimensi, bobot, dan keputusan pengelompokan mangga tampil pada kotak text. 


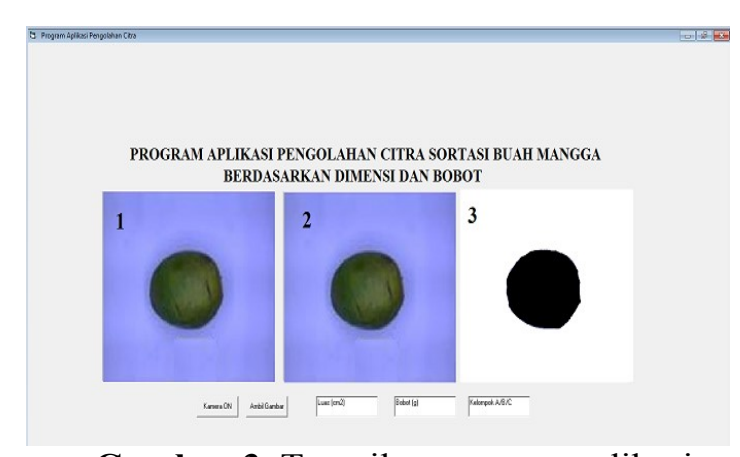

Gambar 3. Tampilan program aplikasi pendugaan dimensi dan bobot mangga

\section{Kalibrasi Program Pengolah Citra}

Pengambilan data dilakukan untuk mengetahui tingkat presisi sistem pengolahan citra dan kamera yang digunakan dalam penelitian ini. Hasil kalibrasi diperoleh persamaan kalibrasi yang menyatakan hubungan antara jumlah pixel terhadap ukuran luas potonganpotongan kertas yang telah ditentukan. Berdasarkan grafik hasil kalibrasi pada Gambar 4 diperoleh hubungan luas dan jumlah pixel membentuk Persamaan 1.

$y=0.0081 x+0.0991$

Dimana:

$x=$ jumlah pixel

$y=$ luas $\left(\mathrm{cm}^{2}\right)$

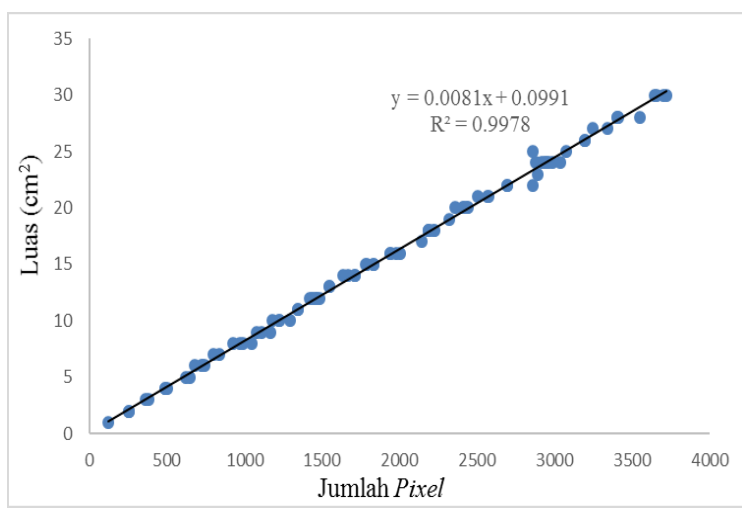

Gambar 4. Kalibrasi luas kertas terhadap jumlah pixel

Validasi Persamaan 1 dilakukan dengan membandingkan luas objek potongan kertas hasil pendugaan program terhadap luas potongan kertas yang sebenarnya ( $r i i l$ ). Hasil validasi Persamaan 1 dapat dilihat pada Gambar 5. Berdasarkan hasil validasi tersebut diperoleh bahwa dengan menggunakan Persamaan 1, program dapat menduga luas permukaan objek kertas dengan nilai RSME sebesar $0,19 \mathrm{~cm}^{2}$.

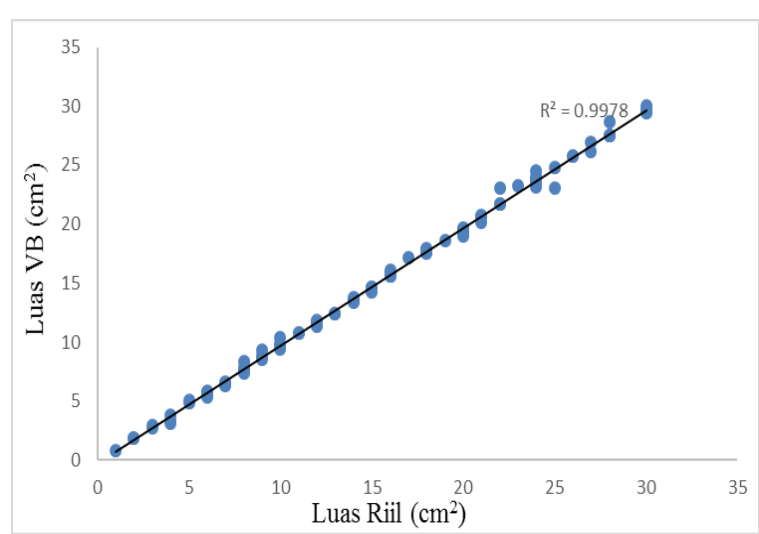

Gambar 5. Validasi persamaan kalibrasi luas objek

\section{Pendugaan Dimensi Mangga}

Persamaan kalibrasi (Persamaan 1) yang telah dibuat digunakan untuk menduga luas permukaan tampak buah mangga. Mangga sebagai benda tiga dimensi dengan bentuk lonjong memiliki posisi tertentu saat keadaan diam di atas bidang datar. Secara umum, dalam keadaan diam mangga berada pada posisi dengan visualisasi pada bidang terluas seperti pada Gambar 6. Sehingga dimensi mangga yang digunakan dalam pengelompokan mangga berdasarkan ukuran adalah luas proyeksi visualisasi pada satu bidang.

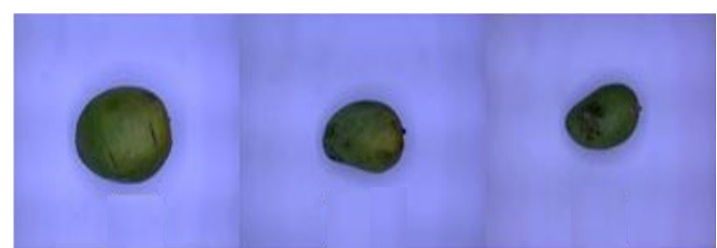

Gambar 6. Tampilan bidang permukaan mangga

Pengujian pendugaan dimensi luas area mangga dilakukan dengan membandingkan luas mangga hasil pendugaan program terhadap luas mangga hasil proyeksi pada kertas milimeter blok. Hasil pengujian pendugaan dimensi mangga dapat dilihat pada Gambar 7. Berdasarkan hasil pengujian ini diperoleh nilai RSME sebesar $0,48 \mathrm{~cm}^{2}$. Nilai kesalahan ini 
diperoleh lebih besar dibandingkan pendugaan luas objek kertas dapat disebabkan oleh dua faktor utama, yaitu kesalahan saat menggambar proyeksi mangga pada kertas milimeter blok dan resolusi kertas milimeter blok yang lebih kecil dibandingkan dengan resolusi gambar.

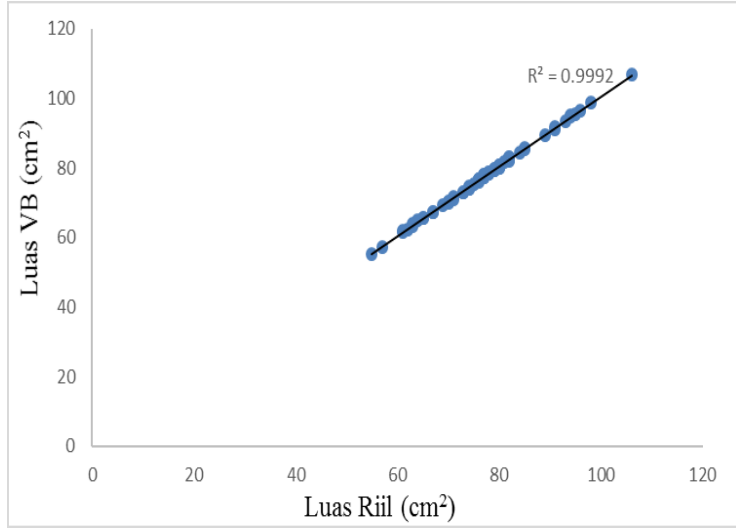

Gambar 7. Pendugaan dimensi mangga

Pengujian menggunakan sampel mangga dengan berat total $100 \mathrm{~kg}$ secara acak yang diambil dari pasar induk Kota Bogor. Sejumlah mangga tersebut dikelompokkan ke dalam tiga kelompok yaitu $\mathrm{A}, \mathrm{B}$, dan $\mathrm{C}$ dengan statistik pada Tabel 1.

Tabel 1. Statistik pengelompokan dimensi mangga

\begin{tabular}{|c|c|c|c|}
\hline \multirow{2}{*}{ Statistik } & \multicolumn{3}{|c|}{ Kelompok } \\
\hline & $\mathrm{A}\left(\mathrm{cm}^{2}\right)$ & $\mathrm{B}\left(\mathrm{cm}^{2}\right)$ & $\mathrm{C}\left(\mathrm{cm}^{2}\right)$ \\
\hline Rata-rata & 95,64 & 78,20 & 64,43 \\
\hline Std. Deviasi & 5,920 & 5,38 & 5,47 \\
\hline Maksimum & 106,67 & 93,01 & 73,14 \\
\hline Minimum & 85,96 & 65,73 & 55,37 \\
\hline Ambang & 95,00 & 75,00 & - \\
\hline Bawah & & & \\
\hline Ambang Atas & . & 95,00 & 75,00 \\
\hline
\end{tabular}

\section{Pendugaan Bobot Mangga}

Secara visual ukuran mangga dapat dibedakan berdasarkan ukuran dimensi, namun perlu diketahui korelasi dimensi tersebut terhadap bobot. Hasil pengujian korelasi dimensi dan bobot mangga (Gambar 8) menunjukkan hubungan yang kurang berbanding lurus. Hal ini terlihat pada nilai $\mathrm{R}^{2}$ hanya sebesar 0,76 . Hubungan luas citra mangga terhadap bobot mangga membentuk Persamaan 2.

$y=4,9452 x-85,928$

Dimana:

$\mathrm{x}=$ luas citra $\left(\mathrm{cm}^{2}\right)$

$\mathrm{y}=\operatorname{bobot}(\mathrm{g})$

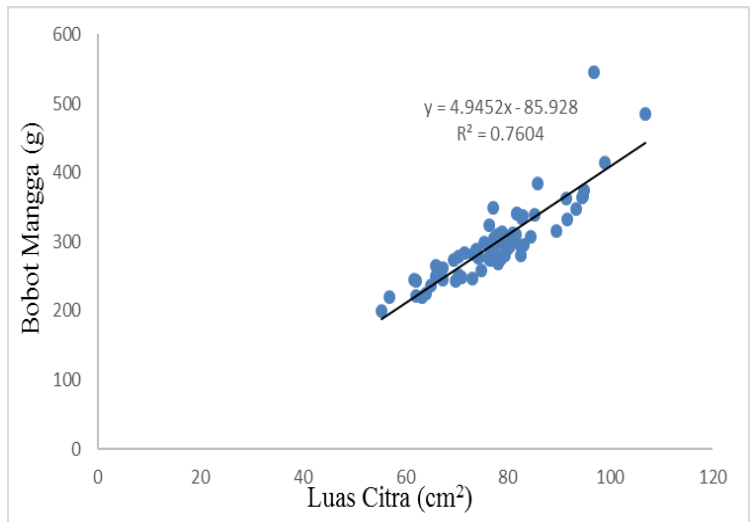

Gambar 8. Hubungan luas citra terhadap bobot mangga

Perbandingan pendugaan bobot mangga menggunakan program berdasarkan Persamaan 2 terhadap bobot riil mangga dapat dilihat pada Gambar 9. Pendugaan bobot mangga ini diperoleh nilai RSME sebesar 26,53 g. Nilai kesalahan ini dapat disebabkan oleh perubahan nilai kadar air yang terkandung dalam buah mangga terhadap umur simpan dan tingkat kematangan buah.

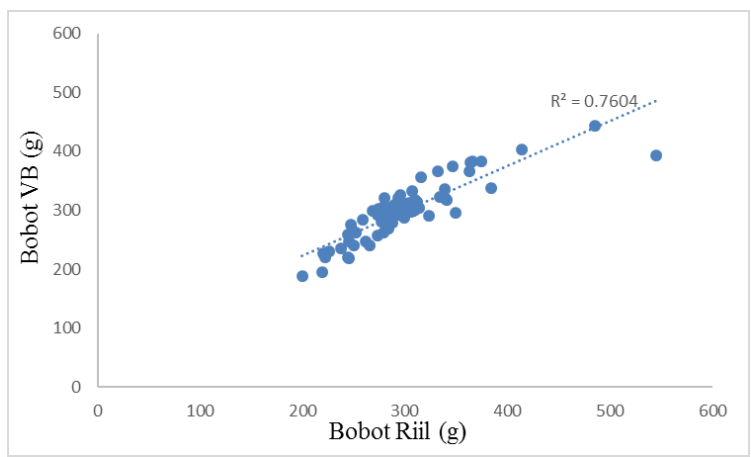

Gambar 9. Perbandingan pendugaan bobot mangga terhadap bobot riil

Pengelompokan buah mangga menggunakan bobot dilakukan berdasarkan statistik sampel buah mangga yang digunakan (Tabel 2). Mangga dibagi ke 
dalam tiga kelompok, yaitu kelompok A, B, dan C. Kelompok A dengan bobot mangga lebih besar dari $350 \mathrm{~g}$, B dengan bobot mangga antara $200 \mathrm{~g}-350 \mathrm{~g}$, dan $\mathrm{C}$ dengan bobot kurang dari $200 \mathrm{~g}$.

Tabel 2. Statistik pengelompokan bobot mangga

\begin{tabular}{lccc}
\hline \multirow{1}{*}{\multicolumn{1}{c}{ Statistik }} & \multicolumn{3}{c}{ Kelompok } \\
\cline { 2 - 4 } & $\mathrm{A}(\mathrm{g})$ & $\mathrm{B}(\mathrm{g})$ & $\mathrm{C}(\mathrm{g})$ \\
\hline Rata-rata & 412,0 & 296,8 & 233,3 \\
Std. Deviasi & 67,9 & 24,1 & 15,5 \\
Maksimum & 545,4 & 349,2 & 249,0 \\
Minimum & 362,8 & 250,1 & 199,8 \\
Ambang Bawah & 350 & 200 & - \\
Ambang Atas & - & 350 & 200 \\
\hline
\end{tabular}

\section{KESIMPULAN DAN SARAN}

\section{Kesimpulan}

Berdasarkan hasil penelitian ini dapat disimpulkan bahwa:

1. Aplikasi pengolahan citra yang telah dibuat mampu untuk mengelompokkan mangga berdasarkan dimensi dan bobot.

2. Pendugaan dimensi luas permukaan menggunakan aplikasi pengolahan citra dapat diterima dengan nilai $\mathrm{R}^{2}$ sebesar 0,99 dan nilai RSME sebesar $0,19 \mathrm{~cm}^{2}$.

3. Pendugaan dimensi bobot mangga menggunakan aplikasi pengolahan citra yang telah dibuat memiliki $\mathrm{R}^{2}$ yang dihasilkan hanya sebesar 0,76 dan nilai RSME sebesar 26,53 g.

\section{Saran}

Program aplikasi pengolahan citra perlu dikembangkan lebih lanjut agar memiliki tingkat akurasi yang lebih tinggi. Penelitian ini dapat dilanjutkan untuk penggabungan aplikasi ini dengan sistem mekanik mesin sortasi buah.

\section{UCAPAN TERIMA KASIH}

Ucapan terima kasih peneliti ucapkan kepada Kemenristek Dikti yang telah membiayai kegiatan penelitian ini melalui hibah penelitian tahun 2019 pada skema Penelitian Dosen Pemula.

\section{DAFTAR REFERENSI}

Ahmad, U., Rudy, T., \& Suhil, M. (2008). Pengembangan Mesin Sortasi dan Pemutuan Buah Jeruk dengan Sensor Kamera CCD. Prosiding Seminar Nasianal Teknik Pertanian 2008 Yogyakarta, 18-19 November 2008, $1-12$.

Anugrahandy, A., Argo, B.D., \& Susilo, B. (2012). Perancangan Alat Sortasi Otomatis Buah Apel Manalagi (Malus sylvestris Mill) Menggunakan Mikrokontroler AVR ATMega 16. Jurnal Keteknikan Pertanian Tropis dan Biosistem, 1(1), 1-9.

Jain, R., Kasturi, R., \& Schunck, B. G. (1995). Machine vision. New York: McGraw-Hill.

Kastaman, R., Marsetyo, Sunarmani, \& Somantri, A.S. (2008). Aplikasi Pengolah Citra d engan Basis Fitur Warna "RGB" untuk Klasifikasi Buah Manggis. Jurnal Bionatura, 10(3), 273-291.

Pramanta, F.D., Susilo, L.W., \& Fahmi, M. R. (2017). Sistem Cerdas Penyortir Apel Berdasarkan Warna Dan Ukuran Berbasis Mikrokontroler Arduino. Prosiding SENTRINOV 2017, 216225.

Soedibyo, D.W., Ahmad, U., Seminar, K. B., \& Subrata, I. D. M. (2010). Rancang Bangun Sistem Sortasi Cerdas Berbasis Pengolahan Citra Untuk Kopi Beras. Jurnal Keteknikan Pertanian, 24(02), 67-74.

Thiang, L.I. (2008). Otomasi Pemisah Buah Tomat Berdasarkan Ukuran dan Warna Mengunakan Webcam Sebagai Sensor. Prosiding Seminar Nasional 
Ilmu Komputer dan Aplikasinya SNIKA 2008, 1-5.

Wiharja, Y.P., \& Harjoko, A. (2014). Pemrosesan Citra Digital untuk
Klasifikasi Mutu Buah Pisang Menggunakan Jaringan Saraf Tiruan. IJEIS (Indonesian Journal of Electronics and Instrumentation Systems), 4(1), 57-68. 